\title{
FRONTLINE POLICE EMPLOYEES' SOCIAL CONSTRUCTION OF CLIENT SERVICE
}

\author{
GJ SCHWARTZ \\ WJ SCHURINK \\ KJ STANZ \\ Karels@uj.ac.za \\ Department of Human Resource Management \\ University of Johannesburg
}

\begin{abstract}
The social construction of frontline employees' client service plays a major role in organisational success. This study illuminated why frontline personnel are reluctant to accept organisational change which is in line with new policing philosophies. Applying modernist qualitative methodology, and particularly grounded theory within a case study design a 'process satisfaction model' was developed with the aim to improve employee satisfaction with internal processes and ultimately service delivery. This model may be used for change in the South African Police Service (SAPS) and other government departments.
\end{abstract}

Key words: Leadership performance, client service, organisational change and modernist qualitative methodology, grounded theory

It is clear from the literature that police agencies all over the world are striving for policing methods that would satisfy community needs (McKenzie, 2005; Geldenhuys, 2005; Stevens \& Yach, 1995; O'Toole, 2004, Wood 2005; Puthpongsiriporn \& Quang, 2004; Egharevba, 2005; Chetty, 2004). A definite trend advocating the move away from traditional crimefighting techniques has developed over the last few decades, in an attempt to involve communities and to improve service delivery. This "move" resulted in various philosophies of policing and problem-oriented policing, community policing and partnership policing emerging as possible solutions to serve communities better (Stevens \& Yach, 1995). However, attempts to change police behaviour to suit these new philosophies take time and are not always successful (Stevens \& Yach, 1995). South Africa too has been struggling to establish a client-driven policing culture in its South African Police Service (SAPS). The first democratic election in 1994 did not automatically bring about an acceptable policing system that could cater for all South African citizens. In 1996 the South African government adopted the National Crime Prevention Strategy (NCPS) to serve as a framework for a multi-dimensional approach to crime prevention. The NCPS is based on comparative international research and pays attention to particular South African factors which underline high crime levels. Crime levels in the country are affected by many of the same universal factors which manifest themselves in other countries (Department of Safety and Security, 1996). In admitting that there is no single cause of crime in South Africa, the NCPS identified the following underlining factors among others:

- Crime levels increase during periods of political transition - based on comparative research conducted in the former Soviet Union and Ireland.

- The new democracy inherited the entire government service, including a racially biased, disproportionate distribution of criminal justice resources.

- Insufficient and ill-equipped personnel, combined with outdated systems and fragmented departments have contributed to a system that was unable to provide a satisfactory service to all the people of South Africa (Department of Safety and Security, 1996).

In a further effort to establish a client-driven policing culture the SAPS has reviewed its mission and vision statements to align them with the new Police Service Act, 1995, and in accordance with the Constitution of the Republic of South Africa, 1996
(Act 108 of 1996). A service charter was also launched in 2002 to commit the SAPS to an improved service delivery to victims of crime (De Beer, 2002) and in the same year, human and physical resources were redistributed to various police stations in an effort to bring about better service delivery to communities (SAPS Circular, 2002). In addition to spreading resources more evenly the SAPS also adapted its policing philosophy to include community policing (through sector policing) in an attempt to be more professional in its service delivery. This has not always been successful as police officers tend to concentrate more on the procedures of how to do the job than on the product they deliver to the public (Department of Safety and Security, 1997).

Brown (in Dantzker, 1997) warns that although organisational change towards professionalism improves the organisation, it tends to have a minimal effect on the line officer. In fact, the situation as far as the SAPS is concerned is far from ideal. Despite the implementation of sector policing and the service charter numerous complaints of poor service by the East Rand Police Service $^{1}$ (ERPS) are lodged. Police managers and commanders are indeed concerned about the quality of its services. There has also been considerable speculation as to the reasons for this apparent poor service delivery (Schwartz, 2004). Most senior officers believe that there is an overall lack of discipline and that the so-called demilitarisation of the SAPS is responsible for this poor service delivery (Schwartz, 2004). They believe that although police officers are competent, they do not want to provide a professional service because it demands more effort and input from them and that members have thus adopted a bad attitude towards service delivery (Schwartz, 2004).

Research confirmed that client-service training improves knowledge of client service but has very little effect on improving attitudes towards clients in the long run (Schwartz, 2004). This finding is supportive of the statement of Swanepoel, Erasmus, Van Wyk and Schenk $(2000$, p. 79) that "...the ability to learn is one thing; the will to actually perform well is something quite different." It is not simply a matter of whether or not police officers are able to do their job, but also whether or not they are committed to doing it. Factors such as employee-manager relationships, organisational culture, employee empowerment, job satisfaction and commitment to the job, all play a role in whether or not police personnel want to provide a better client service. A degree of resistance to provide better service is surfacing amongst ERPS employees (Schwartz, 2004). 
While these factors (which also impact on organisational change) are known to the SAPS very little research has been conducted to advise policy makers of individual needs for the future police service. Fourie and Reynecke (2001) listed a number of factors that pose challenges to organisational change, and mention that the police should know the social make-up of its employees as it influences their morale. However, not much has been done to understand how individual police officers feel about change although some research has been conducted in the organisational change field ${ }^{2}$ (Marks, 2003; Kiley, 1997; McNeil, 1995). It should be clear that if the SAPS is striving to implement any change in police strategies, philosophies and/or activities it would be wise to make an attempt to understand how their employees are feeling about the change and this is exactly why this study was done. Moreover, the reasons why police officers don't want to change were explored and therefore a much closer look was taken at the perceptions of police officers regarding what is needed to convince them to change their behaviour.

The following paragraphs explicate the research approach of the study. It elucidates the data gathering methods, the research methodology and data gathering and - analysis procedures applied.

\section{RESEARCH DESIGN}

\section{Research approach}

A modernist qualitative research approach was followed since it is committed to understanding social phenomena from the actors' own perspectives and examining how they experience their world. Ontologically and epistemologically, this approach regards social reality as what research participants perceive it to be (Taylor \& Bogdan, 1998), and seeks to understand (verstehen) by applying qualitative methods such as participant observation, in-depth interviewing and others yielding descriptive data (Taylor \& Bogdan, 1998). More specifically a grounded theory approach was used, within a case study design to develop a model that could be utilised to explain how employees felt about changes in the SAPS and that could be used to accomplish the aim of the study namely, to improve service delivery within the ERPS.

In order to determine why police offers resist change, it was necessary to understand that their social construction of client service is built on their own meanings, experiences, understandings, ideas, constructions of reality, social and cultural practices and processes, ethical values and belief systems. Epistemologically, the assumptions about knowledge and how it can be obtained or produced (Myers, 1997), rests on the belief that scientific knowledge is built by exploring and describing the ERPS's experiences and perceptions of their service to clients by applying unstructured methods ${ }^{3}$ that would enable capturing the richness of their social construction of service delivery.

As Mouton (2002, p. 38) points out, qualitative researchers should "continuously strive to obtain the optimal truthful and valid findings". Schwartz (2007) tried to stay as close to the truth as possible in his observations and interpretations. This was seen as one of the most important ethical obligations of the study. This requires one to acknowledge any personal bias and interpreting findings in such a way that it accurately reflects the participant's reality. To accomplish this ethical obligation, Schwartz (2007) returned to the subjects at critical points of data interpretation to ask for "clarification or validation" (Liehr \& Marcus, 2002, p. 157 in Smith, 2004, p. 37).

Other equally important ethical standards that were adhered to were the basic ethical requirements as set by Bachiochi and
Weiner (2002). Namely firstly, that no harm should come to an individual due to his or her participation in a research study; secondly, that the participant is fully informed of any potential consequences of his or her participation (informed consent); thirdly, that invitees understand their participation is voluntary; and, finally, that, all reasonable measures are taken to ensure the anonymity and confidentiality of the data.

Participants were eager to participate in discussions which could mainly be contributed to four reasons. Firstly, Schwartz was known to most participants as a reliable and trustworthy person, and thus there already was a relationship of trust between them; secondly, participants were given a full explanation of the study, how it would be conducted, the time that would be required from each participant and group and what would be done with the findings, thirdly, a promise was made to participants that anonymity and confidentiality would be maintained and nothing would be published without their consent, which made it easier for them to open up to him, and fourthly, Schwartz indicated that he also participated in the study by writing an ethnographic essay about his experiences.

In line with the research approach a case-study design was utilised. Neuman (1997 p. 331) explains the value of the case study as follows: "... gather a large amount of information on one or a few cases, go into greater depth, and get more details on the case being examined." In order to explore the experiences and perceptions of police officers in the ERPS it was essential that the study be conducted on East Rand police officers who receive training at the decentralised training centre (the research setting). Denzin and Lincoln (2003, p. 137) call this type of study an "instrumental case study" because it is aimed at obtaining insight into a specific issue. The case only plays a supportive role. The purpose of Schwartz's case study design was to serve as an "instrument" to improve understanding of a topic or to refine theory (Swanson \& Holton, 1997).

Theoretical sensitivity is a "personal quality of the researcher" and it is a reflection of one's "awareness of the subtleness of the meaning of data" (Strauss \& Corbin, 1990, 41). It is the combination of professional and personal experience and one's reading of literature that influences one's theoretical sensitivity (Schurink, 2005). Strauss and Corbin's (1990) emphasis on theoretical sensitivity was heeded in the research. As they state an important feature of grounded theory is theoretical sensitivity, which refers to a personal quality of the researcher and relates to understanding the meaning and subtlety of data. Theoretical sensitivity is thus the insight with which a researcher comes to the research situation. Such insight should be conceptual rather than concrete. It is often referred to as a creative aspect of grounded theory and involves the researcher working in an area to obtain experience and expertise. Thus for Schwartz (2007) experience in the organisation weighed more than knowledge of it, as experience impacted more heavily on his understanding of terminology and participant vocabulary that were specific to the police. By gaining theoretical sensitivity the researcher was able to recognise important data and formulate conceptually dense theory. As Bogdan and Biklen (1998) state: "Good researchers are aware of the theoretical base and use it to help collect and analyse data. Theory helps data cohere and enables research to go beyond and aimless, unsystematic piling up of accounts."

The study applied the grounded theory approach of Strauss and Corbin (1990). Such theories represent intellectual tools that are developed to illuminate particular social phenomena within a particular field of study.

As recommended by Swanson and Holton (1997), special care was taken in using existing literature and theory. Firstly the literature was scanned to gain an understanding of the 
state of the art of service delivery in the police sector. This enabled Schwartz to formulate a relevant problem statement. Through the process of data gathering and analysis Schwartz then gradually searched deeper and deeper into specific issues raised by research participants. This assisted Schwartz in categorising the data and to gain a deeper understanding of the themes that were identified so as to be able to refine focus, questions and methods. Even after the data was categorised did Schwartz refer to the literature to better understand the themes that emerged during data analysis and eventually to find "supporting evidence" of the emerging substantive theory.

\section{Research methodology}

Participants. Permission to conduct the study in the East Rand SAPS was granted by the Area Human Resource Manager. No limitations or restrictions on any information, whether sensitive or confidential, were imposed, but special caution was taken not to disclose any confidential information that could jeopardise any criminal investigation or that could lead to civil action as a result of the study. The training centre where Schwartz (2007) worked was the research setting where the study was undertaken. Initially all frontline members who were receiving training at the ERPS training centre formed part of the study. Both civilian personnel and functional police officers working at different departments within the East Rand such as detective units, specialised units, crime-prevention units and administration departments were included. A large number were shift workers who attended to complaints in community-service centres or who were placed out in the field. Snowball sampling was applied to reach particular participants. Table 1 illustrates the demographic profile of participants.

TABLE 1

DEMOGRAPHIC INFORMATION OF RESEARCH PARTICIPANTS

\begin{tabular}{lcclc}
\hline Participant & $\begin{array}{c}\text { Race } \\
\text { and } \\
\text { Gender }\end{array}$ & Rank & \multicolumn{1}{c}{ Type of Duties } & $\begin{array}{c}\text { Years } \\
\text { of } \\
\text { Service }\end{array}$ \\
\hline P1 & W/M & Inspector & Uniform response & 13 \\
P2 & W/M & Inspector & Detective & 15 \\
P3 & A/F & Inspector & Detective. Firearm Licences & 12 \\
P4 & C/F & Captain & Complaints, Administration & 12 \\
P5 & W/F & Inspector & $\begin{array}{l}\text { Human Resources, } \\
\text { Complaints }\end{array}$ & 16 \\
P6 & W/M & Sergeant & Uniform response & 13 \\
P7 & W/M & Captain & $\begin{array}{l}\text { Uniform, CSC and } \\
\text { Complaints }\end{array}$ & 12 \\
P8 & & W/M & Captain & $\begin{array}{l}\text { Management, } \\
\text { Administration }\end{array}$ \\
\hline
\end{tabular}

\section{Methods of data gathering}

Data collection was done in various ways. Focus-group interviews and in-depth, one-on-one interviews were conducted. Punch (1998, pp. 174 - 175) asserts: “...the interview method for data collection is a good way of assessing people's perceptions, meanings, definitions of situations and constructions of reality." Participant observation was used and field notes were compiled and analysed. Unsolicited (where researchers have no input) official police documents such as the police performance enhancement plans of members and solicited documents (eg. the researcher requesting essays and/or memoranda) were used to gain further insight into the actual performance of actors. Using these various data sources enabled triangulation, which in turn enhanced the quality of the research (Flick 2007). Schwartz's own experiences and perspectives served as an additional data source.

\section{Procedure}

Data capturing and storing. Data was captured in the form of field notes, tape recordings and transcriptions thereof. Digital photographs were taken by Schwartz of the research setting. In this way an attempt was made to capture the spaces between research participants and Schwartz, as well as the "atmosphere" within which the interviews were conducted ${ }^{4}$. Kanstrup (2002) noted that interview responses that are studied against the photographs taken at the scene of the interview could help the researcher to re-evaluate the overtones and circumstantial detail of what took place.

On the whole the research was guided by Silverman (2000, p. 142) who suggested a broad route to data capturing that included: "Short notes made at the time, expanded notes made as soon as possible after each session, a fieldwork journal to record problems, and ideas that arise during each stage of fieldwork, and a provisional running record of analysis and interpretation." These field notes were captured on Schwartz's notebook using Microsoft Word software. A hard copy of the field notes was then printed and filed in a folder for analysis. Focus-group and in-depth interviews were also recorded on tape by using a small handheld voice recorder. Recordings of interviews were immediately transcribed after the completion of an interview. These transcriptions contained the whole interview. A summary of each interview was then made (Glaser \& Strauss, 1967) that contained theoretical notes on emerging patterns and similarities. Printouts of transcripts, solicited documents, Schwartz's ethnographical essay, back-up data, tape recordings and photographs were filed and safely stored personal memos were handwritten and kept at hand to enable easy access to information whenever Schwartz needed to study them or to add something to them. Data was mainly stored on computer, in back-up files on compact disc and in its original form.

Data analysis and interpretation. Data analysis started after the first focus-group interview was conducted. This was done to sort and order the vast amount of data. A grounded approach was followed because this approach is ideal for studying social change (Parry, 1998 in Schurink, 2004). Strauss and Corbin (1990) developed a systematic coding process to compare data in a variety of ways. Their developments provided for strict application of a process of open coding, axial coding and selective coding.

Open coding occurs when data is broken down and conceptualised (Holloway \& Wheeler, 2002). Sentences are taken apart in order to find similarities and differences which in turn will facilitate the identification of central ideas (mostly referred to as discrete concepts). Open coding was applied as soon as the first interview was completed. This process gave rise to 21 emerging themes. Axial coding is done by means of a "coding paradigm involving conditions, context, action and/or interactional strategies and consequences" (Strauss \& Corbin, 1990, p. 96). It is a process where connections are made in new ways between the formulated categories and their sub-categories (Priest, Roberts \& Woods, 2002). Axial coding is also aimed at making connections between a category and its subcategories. It was important at this stage understand the context in which participants provided their client service because it could be useful to develop categories (Denzin \& Lincoln, 2003). This type of coding was applied by purposefully reducing the number of categories identified during open coding. This in turn was done by reconsidering each property and category and by reevaluating the terminology used to describe the understanding of the data. Secondly, each theme and its properties or concepts was studied to try to understand what was going on and why it happened. Concepts revealed the circumstances that caused the phenomenon enabling Schwartz (2007) to identify 8 core categories. Central to the identification of core categories was the use of memos. The process of memoing was used to reflect on the data and thus to make more sense of it (Locke, 2001). This enabled Schwartz to "see" the relationship between categories 
and properties. Dick (2002) explains that memoing is the process of adding relationships to link categories or properties with each other.

Tying these main themes or core categories together in one central theme was the next step. Selective coding occurs when all other inferred themes are integrated into one theme (Strauss \& Corbin, 1990). A conceptual framework of themes builds up to a single storyline covering all inferred themes (Holloway \& Wheeler, 2002). The result of selective coding is manifested in the relationship between concepts or theme categories and core categories from which a single storyline is built.

As already indicated, Schwartz referred to existing literature at several stages. During the axial coding phase a preliminary literature study on the emergent themes was done to determine the interconnectedness of these themes. It was important to know whether or not there was any theme that was totally unrelated and which might have demanded further investigation. In an attempt to find the single storyline Schwartz turned to the relevant literature once again during the selective coding stage (Holloway \& Wheeler, 2002). The existing theoretical concepts were reviewed to get clarity on the emerging core categories namely organisational change, managing change, resistance to change and development for change. Some police studies that were conducted within the SAPS were also studied and Schwartz took a close look at the world of the frontline employee in the organisation. Once the data was analysed and the literature review completed he started to work towards developing a substantive model grounded in the data. This model applied to front-line employees' experiences and behaviour in the SAPS. The relationship between theoretical concepts and research generally focus on theory. In the study it was important to point out that this argument needs to include other constructs as well, in this case, definitions, typologies and models.

In inter-subjective research the researchers themselves serve as research instruments (Schurink, 2005). Qualitative researchers are thus part and parcel of the world they study and they accept that this influences the data they collect. Instead of trying to eliminate their influence on their research subjects and data collection, they account for it in their data analysis and accounts. More importantly they believe that research demands from them a level of reflection upon the ways in which the findings of the study is formed by the research process itself (Murphy \& Dingwall, 2003).

In reflecting back to collecting data Schwartz was fortunate to have had quite a number of 'ears' at his immediate disposal to listen to and to respond as peer debriefers. These included a colleague and fellow facilitator, a seasoned and experienced training manager, and his wife Karin which intermittently offered valuable perspectives. A diary was kept and intermittently updated as events occurred in the course of the study. This served as an audit trail of decisions and occurrences to enhance credibility of the study's findings as in Pretorius (2006).

\section{FINDINGS}

\section{Open coding}

The excerpts used in this article portray the general feeling of frontline employees. The following obstacles identified by the research participants lay at the root of poor service delivery:

Lack of managerial skills. Managers were regarded as being inexperienced and incompetent to lead in the face of change. Due to their inexperience managers tended to make bad decisions. This was especially true of the newly appointed managers. Managers holding the same rank as their subordinates were also not regarded as good enough for management positions in the SAPS. In general, participants felt that management was not able to address the problems in the workplace. They were also not able to discuss their problems with their commanders because commanders cannot solve these problems and later on use the same issues raised by subordinates against them.

Even maintaining a basic level of discipline among their subordinates was a challenge that most line managers have failed to meet. Many do not understand how to operate the new disciplinary system, and even if they do, they feel they do not have sufficient organisational support. Newly appointed managers were not suitably equipped and supported to effectively manage those in their command. Older managers, on the other hand, were perceived to be more empathic towards their subordinates.

There was very little middle- and lower-level management accountability and blame shifting was a common practice when the quality of service was being questioned. Station Commissioners did not visit community service centres after hours to establish the level of client service and also did not enforce discipline out of fear for accusations of racism.

Another reason for poor relations and poor performance was the fact that non-performing members were simply being transferred without addressing their non-performance. It seems as if personnel's non-performance was tolerated and/or accommodated to avoid conflict, but participants regarded this don't care attitude of colleagues as a result of lack of managerial skills.

Participants were particularly disappointed in the promotion policies and processes of the organisation since they strongly felt that the people who were promoted were not always able to do the job, while those who could do the job were not promoted. This application of affirmative action policies and patronising attitude resulted in a lowering of standards, a growing feeling of distrust and a loss of respect for authority. Some openly expressed their dissatisfaction and distrust in their managers as was evident in the following excerpt:

P3 (African Female Inspector): "They don't promote people who are competent. What is the use if they say they are balancing the equity, but the people they promote to balance the equity are not competent.... The station standard went down from 4- to 1-star performance. I feel ashamed of what is happening; people will think black females cannot do the work because she was an affirmative action appointment".

Lack of support. Participants in general did not trust or rely on the organisation's support system because they felt that the confidentiality of matters could not be guaranteed. Members of the Employee Assistance Services (EAS) had to report matters to the Area Commissioner and/or Station Commissioners. Such matters further had to be shared with direct supervisors of employees. Participants felt that these socalled confidentiality assurances were misleading. Managers at stations were largely to blame for this. Front-line staff members tried very hard to avoid the station support systems and dealt with their problems privately by seeking private psychologists or dealing with it on their own.

Participants blamed the Area Management for their stagnation in the organisation and had a general distrust in the Area Management. They felt that when changes were made in the organisation senior managers were not affected by it. Senior managers were thus perceived to be unfair and inconsistent in their handling of matters. Participants also felt that they couldn't direct their problems to the Area Management, because issues such as collective grievances were simply swept under the carpet. Managers' inability or unwillingness to solve their personnel's problems added to further distrust, alienation and low employee morale. 
The performance enhancement process was perceived to be a tool for managers to manipulate their subordinates. It was the same performance measurement instrument that exposed the unfair and inconsistency of management judgement. Participants indicated that this kind of behaviour was responsible for poor manager/employee relations. They perceived station managers as antagonistic and unable to handle criticism. Managers branded employees with opposing views as troublemakers or as "problem children" ${ }^{5}$. Participants regarded their managers as insensitive regarding feedback from employees. Managers' relations with particular staff members were therefore questioned when promotions and performance appraisals were announced.

P8 (W/M), essay written in January 2006: "My experience is that my manager supports and agrees with me on issues when he is in my presence, but later when he is in the company of others, he also agrees with them. He pretends to care about personnel, but he phones the promotion panels to influence their short-list selection. I have seen its effect on a colleague. He has ruined her career..."

Poor departmental coordination and cooperation. Front-line personnel did not know or understand the internal processes of other departments and the way in which these were related to what their own tasks entailed. This was the cause of much frustration at crime scenes. The sequencing of crimescene experts, photographers, uniform members, vehicle tow-in services were at times not well coordinated.

Another issue that impacted negatively on service delivery was the poor interpersonal relations between members. This could have serious consequences in the field where patrol officers need to depend on each other for assistance. Front-line officers indicated that when they ask for assistance in cases of serious crimes (such as armed robbery), the other patrol officers did not even respond to such radio calls. Others did not assist their colleagues who got promoted because they regarded the promotion itself as unfair.

There was also outspoken hostility between detective units and uniform members due to the egoistic and arrogant behaviour of senior detectives towards their uniform counterparts. The core of this friction was the perception of detectives that they were more skilled and more competent than the "plat kepse" ${ }^{6}$ in spite of the organisation's efforts to remind all police officers and departments to work towards the same objectives. There was also a degree of tension between old- school police officers and new police officers who recently joined the organisation. Old-school members were used to instructions, while newer personnel did not want to be told what to do. Adding to the dilemma was the fact that nonperforming members were being transferred to other units or sections without addressing their non-performance attitude or behaviour. The following excerpt is illustrative of this:

"In private companies they have this policy that if you don't deliver they cannot keep you in the company. It's because they know we don't deliver! But here, if you are useless, they just move you from one unit to another. We move the problems from one unit to another".

Lack of resources. Poor resource management was a huge concern to front-line staff. Change was implemented and driven without providing the necessary logistical resources to affect the change. Research participants claimed that they found it hard to obtain the necessary resources to deliver quality service. Because of the serious lack of resources employees had to work under circumstances that hampered their performance and made them feel ashamed of their occupation. For example they were instructed to implement new service- delivery strategies without having the floor space for it. Personnel were placed in overcrowded offices where there was no sense of privacy, personal space or confidentiality of any sort or proper furniture.
The study showed that it was difficult to secure proper equipment or even vehicles. At some stations members were even expected to work without bullet-proof vests. This left these police officers with the awkward option to either slow down their reaction against crime, by waiting until the situation is safe or to jeopardise their own lives. Others stated clearly that they were not being paid enough to risk their lives and the security of their families to take on armed robbers without the proper equipment and arms.

Lack of information and communication. In general, participants felt that front-line employees were not well- informed of what was happening within the organisation or even of what was happening in their policing area. Front-line staff members had to be aware of actuality matters and of what were in the news. Participants felt that they were regarded as "stupid" because they received no proper information from management. They indicated that they did not understand the changes made in the police service as it sometimes did not make sense. The situation worsened to such an extent that front-line workers joked about which new changes will 'hit' them when they reported for duty. Furthermore, participants felt that front-line employees were not properly informed on acceptable service standards. Their communication with the public was usually restricted to police matters because that is a topic they felt comfortable with.

Frontline employees found it hard to implement new policing strategies because as they explained they were not informed in time of such changes. They therefore did not have enough time to prepare themselves or their families for changes that affected their private lives. Police officers felt strong about the fact that their needs were not acknowledged and that their contribution to policy development was ignored. They felt left out and as a result became alienated from the system.

Continuous feedback to front-line personnel was regarded as an empowering measure that cannot be ignored. Participants felt that they couldn't approach their managers to obtain information because their managers didn't know either. Supervisors and managers couldn't explain new change drives and provide employees with their own interpretations of what was happening. Junior managers were the real culprits, they added, because they couldn't guide, mentor or inform their subordinates. Instead they were just 'bossy' and not being in touch with people at grass-root level. That was also why they did not support organisational change.

The situation was deteriorating even further because front-line staff had lost their interest in formal internal communication. They didn't attend station lectures where important information was shared simply because they didn't want to. However, Station Commissioners had to keep their personnel informed to address uncertainties. Participants admitted that they didn't put in much effort from their side to become more informed or work together to change things. This negative situation was clearly explained in the following excerpt:

"Changes are not communicated to members in time or not well enough. Members are not kept up to date. I don't feel part of any changes in the police service, because everything just comes as an instruction. If we ask them the response is that it is an instruction, we have to do it, but we don't understand why we do it. If management wants to introduce something they must go to the members at the ground and not think about their management positions, and hear how they are feeling about it".

The study also revealed that first-line managers were not aware of the existence of some policies and its content. Yet, it should be noted that, when policies are drafted it was sent via e-mail to all relevant role players and even to all e-mail addresses on the police communication network to obtain comments and suggestions regarding its purpose and suitability for implementation. 
Protesting behaviour. Front-line staff members expressed their dissatisfaction, anger and their resulting negative attitude towards management through their behaviour. They protested against unfair internal treatment by either openly restricting their client service or covertly by working slowly or omitting parts of their job. Front-line staff members also showed their dissatisfaction through unbecoming conduct, and by openly rejecting the authority of senior personnel at times. To show their dissatisfaction with the rewarding mechanisms of Performance Incentives and Promotion front-line employees restricted their services to the basics only in very much the same fashion as labour's work-to-rule principle. They provided poor service as a means of getting back at management for not rewarding their efforts. Research participants identified the inconsistent application of policies and instructions as the reason for their unwillingness to do more for clients.

Instead of addressing the problems hampering change they rather joked about policy changes and cheated their supervisors in the implementation of such initiatives. Another problem was that inspection teams that had to monitor implementation of new directives took note of deviations but condoned such negative conduct by turning a blind eye to it. Members book offsick to escape the effects of change in the police department.

A further disturbing tendency was that some frontline police officers were so demoralised that they had passed the stage where they cared about the organisation or the role they were supposed to play in it. As a result they were no longer concerned about change in their working conditions. Some of them already reverted to operating private businesses while they were at work. They openly stated that they would stay in the organisation for as long as possible, but in the mean time they will carry on operating their private businesses. This negative behaviour could be attributed to pessimism that resulted from slow career growth. Managers were blamed for being inconsistent and biased in their application of internal policies and this drove members away:

P8 (W/M), field note, 14 September 2005: "I have witnessed the effect of not receiving a performance bonus. Three colleagues of equal rank who do the same work, having the same job description and performance plan, who received the same supervisor rating were assessed by the same evaluation panel. One of them received an incentive and the other two did not. They felt ashamed and left out. The following year they were asked to apply for the same type of incentives. One individual replied that he was no longer interested in such nonsense. The other one applied for a transfer."

TABLE 2

THEME CATEGORIES OF OPEN CODING

\begin{tabular}{ll}
\hline Theme category & Theme category \\
\hline Lack of managerial skills & Unfair treatment \\
Poor departmental coordination & $\begin{array}{l}\text { Unsupportive working climate } \\
\text { (sceptical) }\end{array}$ \\
Questionable personnel utilisation & Unsupportive working conditions \\
Resource availability & Escaping effect of change \\
Distrust management & Personnel feel excluded (alienated) \\
Uninformed personnel & Acknowledge Importance \\
Change not understood & Uncertain career future \\
Unclear goals & Low morale \\
Disagreement on change process & Staff not committed \\
Protesting behaviour & Competence \\
Unhappy with rewarding \\
mechanisms
\end{tabular}

Open, Axial and selective coding

Initially a total of 21 themes emerged from the data. These were reduced to eight main themes that emerged from the data during axial-coding. All of these could be linked to employees' dissatisfaction in the organisation. The eight main themes are:

- Objectionable managerial skills

- Distrust in managers

- Front-line staff not well informed

- Employees dissatisfied with internal processes

- Employees have little support

- Personnel questioning their relationship with organisation

- Employees not committed

- Employees lack interpersonal skills

The next and final step was to apply selective coding. After carefully analysing the data, three themes were emerging as a possible theoretical basis. These themes revolved around job dissatisfaction, employee non-commitment and dissatisfaction with the internal processes. It was only after Schwartz had consulted the literature and reverted back to the data that he was able to identify a single emerging core category that could explicitly explain the phenomenon. This core category met the requirement set by Strauss and Corbin (1990) namely to be able to integrate all other inferred themes. It was clear from the data that front-line employees were being managed within a set of rules. These rules were guided by organisational policies and directives which had to be implemented and applied by managers. However, this is exactly where employee dissatisfaction with the organisation originates from, because all managers do not apply organisational policies in the same way and not consistently. Employees' dissatisfaction can be illustrated as in Figure 1.

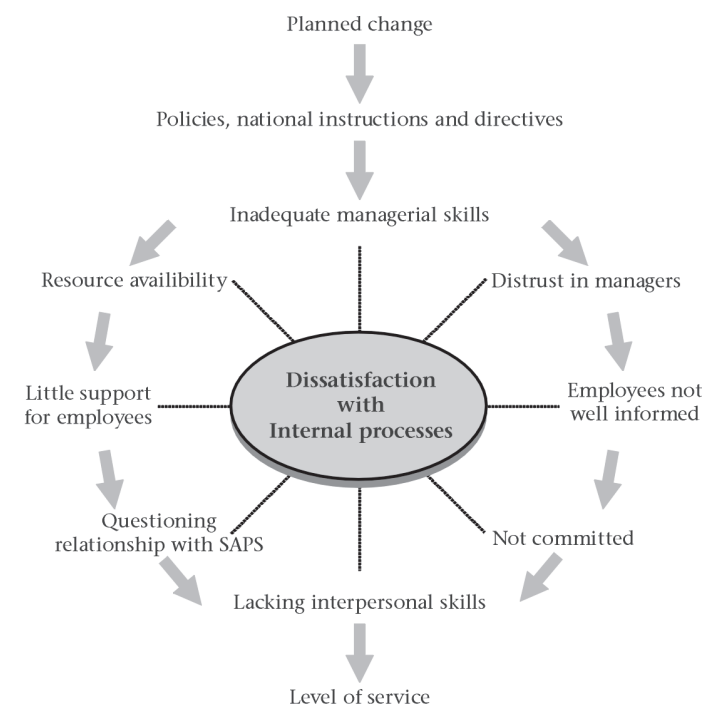

Figure 1: Current application of policies and directives

It is quite obvious that the phrase "dissatisfaction with internal processes" does include all the categories that emerged during axial coding. Dissatisfaction with internal processes as core category mainly emerged from - (i) the application of, and (ii) non-involvement with formulation of internal human resource policies and directives, and not necessarily from changes in policing strategies or the policy instruments themselves. The outcome of this research was the development of a model, the Process Satisfaction Model. This model could explain what was happening in the organisation as far as change and client service was concerned. 


\section{DISCUSSION}

\section{Interpretation}

One has to remember that the SAPS does not recruit clients, but must satisfy them in such a way that they will return and advertise the SAPS with pride (Basson \& Nel, 1998). The SAPS module for improving client service is basic enough for all its employees to understand and is also comprehensive enough for front-line personnel to be able to improve basic service delivery. The training module also focuses on issues that would promote professional and balanced relationships in the workplace. From the South African government's point of view service delivery must meet the customer's expectations. The specific requirements as to the way in which these needs have to be met are indicated in the eight Batho Pele Principles contained in the White paper for transforming public service delivery. They are:

- Consultation with the public in terms of quality and level of service.

- Service standards to be expected.

- Access for all citizens on equal basis.

- Courtesy and consideration.

- Information on services entitled to receive.

- Openness and transparency of how government departments are run.

- Redress the situation if the problem is not solved and offer a remedy.

- Value for money.

Because of the interconnectedness of factors it was difficult to identify the core reasons that gave rise to the general feeling of discontent and poor service delivery in the East Rand SAPS (ERPS). As was evident from the findings police officers' resistance to change could primarily be traced back to the way decisions were made by managers. More specifically, the inconsistent manner in which organizational policy and changing processes were implemented and especially the impact it had on their ability to move vertically and horizontally in their careers and the effect it had on rewarded systems. However, the research participants also felt that they were cut off from internal decision making processes and that their interests and contributions were not acknowledged. Yet, participants admitted that they didn't put in much effort from their side to become more informed or work together to change things.

Their reasons for this dissatisfaction could thus mainly be traced back to the inadequate leadership skills of their commanders, poor working conditions, lack of information and involvement in decision making and lack of proper resources and equipment to address the crime situation more effectively as well as the fact that they experienced feelings of alienation. In the long term this lead to lack of commitment and motivation among the frontline personnel.

The biggest contributing factor to the de-motivation of employees was the criteria used for the awarding of performance bonuses and incentives such as pay progression. Front-line staff accused their supervisors of being biased and of favouritism. Hartle (1995) indicates that the goal of effective performance management is to create an organisational climate in which employees continuously strive for performance improvement. A performance management system should strive to embed acceptable behaviours and values in the way things are done in the organisation. It should therefore be developed with reference to the existing or the preferred culture (Torrington and Hall, 1998). This was not the case in the present study. In fact one of the major contributors towards dissatisfaction with internal processes was the way promotions were handled. Employee commitment can be viewed as "...giving all of yourself while at work". This means that employees should use work-time constructively, pay attention to detail, put in that extra effort and accept change. They should further cooperate with others, engage in self-development, respect trust, have pride in their abilities, seek improvement and give loyal support (Mullins, 1999). Generally speaking none of these requirements for commitment were met by the research participants.

Employee commitment can be characterised by at least three factors. There must be a strong belief in and acceptance of the organisation's goals and values and a willingness to exert considerable effort on behalf of the organisation by the employee (Mourday, Porter \& Steers, 1982 in Swanepoel et al, 2000). Moreover, employees must have a strong desire to maintain membership of the organisation (Mourday, Porter \& Steers, 1982 in Swanepoel et al, 2000).

Martin and Nicholls (1987, in Mullins, 1999) identified three pillars of commitment, each with their own three elements. After analysing the data it was clear that the presence of these pillars and/or their underlying elements were sorely lacking in the present study. In this study, participants have argued that personnel had no sense of belonging. In fact without the opportunity to share in the success of the organization and thus by not being rewarded for good performance; not being involved in decision making processes and not receiving any information to explain changing processes and decision making they felt totally left out and alienated from the system. They experienced no sense of excitement in their jobs and had no sense of pride in their work. What made it worse was the total lack of accountability since those who did not meet performance standards or deviated by not refusing to take orders or worse those who went so far as to run their own private businesses from work were not punished. Research participants had no confidence in management and did not regard managers as competent to lead. In fact a major contributor towards dissatisfaction with internal processes was the way that promotions were handled. Participants felt that promotions were being awarded to employees who did not meet the required level of standard and skill to be effective in their new posts. This resulted was a clear level of distrust in the capabilities of immediate supervisors or of employees.

TABLE 3

THREE PILLARS OF EMPLOYEE COMMITMENT (ADAPTED FROM MARTIN AND Nicholls, 1987, in MulLins, 1999)

\begin{tabular}{|c|c|c|c|c|c|}
\hline $\begin{array}{l}\text { SENSE } \\
\text { OF } \\
\text { BELONGING }\end{array}$ & & $\begin{array}{l}\text { SENSE OF } \\
\text { EXCITEMEI } \\
\text { THE JOB }\end{array}$ & NT IN & $\begin{array}{l}\text { CONFIDENCE } \\
\text { IN } \\
\text { MANAGEMENT }\end{array}$ & \\
\hline $\begin{array}{l}\text { Inform- Involve- } \\
\text { ed ment } \\
\text { in work } \\
\text { place }\end{array}$ & $\begin{array}{l}\text { Share } \\
\text { in } \\
\text { success }\end{array}$ & Pride Trust & $\begin{array}{l}\text { Account- } \\
\text { ability } \\
\text { for } \\
\text { results }\end{array}$ & $\begin{array}{ll}\text { Author- } & \text { Dedica- } \\
\text { ity tion }\end{array}$ & $\begin{array}{l}\text { Comp- } \\
\text { etence }\end{array}$ \\
\hline
\end{tabular}

Service delivery was seriously affected by their dissatisfaction with the situation. Police officers withheld their service from the public and employees stated openly that they will not do anything extra when they don't get an incentive. Some were actually questioning their relationship with the organisation and did no longer see a future for themselves in the SAPS. However, when asked if they actively tried to change things for the better, the tendency was not only that they did not but also that they were no longer interested to do so.

Watson (2003) warns that untrusting management policies and control techniques are likely to be reciprocated with low-trust employee attitudes and behaviour. Such behaviour is often followed by conflict. Other factors that could according to the literature lead to conflict included the following:

- differences in perception of how the real world is seen;

- competition over limited resources from the time of budgeting to allocation and use;

- the nature of work activities where one person's work depends on the work of others; 
- inequitable treatment such as perceptions of unfair treatment in the application of organisational policies;

- violation of territory where departments exceed their responsibility and start doing the work of another department, and

- environmental changes such as changing client demands or statutory requirements (Mullins, 1999).

Judging from the above most of the ingredients for conflict was present in the study. However at the time the study was undertaken the negative feelings and anger expressed by the research participants were mostly kept hidden and seemed to surface only in the form of passive resistance to change manifested as an unwillingness to cooperate with others, blame shifting, lack of respect of and trust in management, ridiculing the system by joking about change, slow response or non response to orders, and disinterest in the organisation.

The question is what role does organisational culture play in change processes. According to the literature there are no "best" and "worst" organisational cultures, and the issue to be addressed is rather how well organisational culture can match and support organisation products or services (Johnson \& Scholes, 1999). In contrast to this Veldsman (2002) asks whether or not organisational cultures can become pathological. The centrality and pervasive influence of organisational culture make the emergence of a pathological culture a threat to the long-term effectiveness and the well-being of the organisation. The source of such pathological cultures rests on the shoulders of the organisation's leadership.

Pathological cultures reflect characteristics that are also found in other organisational cultures, but the difference lies in the extreme manifestation of these characteristics. Veldsman (2002) argues that three types of pathological culture exist, namely: The defensive culture, the reality estranged culture and an ethically numbed organisation. An analysis of the organisational culture of the ERPS showed clear indications of all three of these types of pathological cultures namely:

- The defensive organisation resulting from a neurotic culture characterised by marked inactivity and passivity, unwillingness to for example unwillingness or inability to make decisions, blame shifting, not responding to complaints, turned a blind eye to deviant behaviour of subordinates or did not attempt to do anything to change the negative situation they were in.

- The reality estranged culture resulting from a leadership cadre that does not support and enable organisational members to cope with the new realities the organisation has to face. Behaviour in the form of non-involvement, withdrawal, estrangement, alienation, apathy, an inward withdrawal, a lack of genuine excitement and enthusiasm, an indifference to praise or criticism and a lack of interest in the present or future are common.

- The ethically numbed organisation that looses its ability to make decisions based on generally accepted moral and ethical norms. For example when people choose to engage in private business while they are supposed to patrol the streets. This type of organisation is characterised by opportunism and a loss of any sense of conscience.

Client service was seriously influenced by the lack of commitment of the police employees. Police officers withhold their service from the public and employees stated openly that they would not do any thing extra when they don't get an incentive. However, despite the seemingly insurmountable obstacles encountered in the study concerned efforts should be made to deliver a better service to clients and in the process also improve working conditions for police officers.

In general the study explains the consequences of policy implementation problems found in Krause's (2004) study. It further supports the findings of Van Graan (2005) that there is a breach between national legislation, SAPS policies and directives and the implementation thereof. It illustrated the perceptions and feelings of Front-line personnel including civilian staff members regarding the way they are managed as well as their organisational commitment. Most importantly it offered an explanation of core reasons as to why front-line personnel resisted change.

The findings clearly showed an urgent need for a model to address the factors that gave rise to this dissatisfaction with internal processes. Employee satisfaction was dependent on the internal service quality (Heskett, et.al. 1994). Service quality is therefore dependent on the way that internal processes are executed. This statement is supported by Eygelaar (2004) who summarised the determining factors ${ }^{7}$ of employee performance excellence (and therefore client service) as:

- people management and people satisfaction;

- resources and information management;

- policy and strategy;

- organisation processes;

- customer and stakeholder focus, and

- customer and stakeholder satisfaction.

Schwartz' version of a Process Satisfaction Model (see Figure 2) presented the key components identified in the study. The model clearly shows the important impact of human and social factors, such as motivation, resistance, culture, satisfaction and morale on the functioning of the organisation internal processes and service delivery. This model could be utilised to improve employee satisfaction with internal processes and could ultimately lead to improved service delivery. It could be used to turn the tables around by helping leaders to develop and sustain an environment characterised by:

- effective and accountable management;

- sharing of information and providing regular feedback to employees;

- education and preparation for change;

- respect and tolerance for one another;

- fairness towards all employees especially concerning the implementation of promotion policies and processes. Employees should thus be rewarded in accordance with effort and performance;

- high morale, motivation and commitment;

- trust among employees themselves and among management and employees;

- emotional support by management and among employees;

- involvement of staff in decision making processes that affect them;

- accountability and a proper disciplinary system;

- commitment to the vision, mission, and values of the organisation;

- co-operation and coordination with each other as well as other departments

- effective and accountable resource management

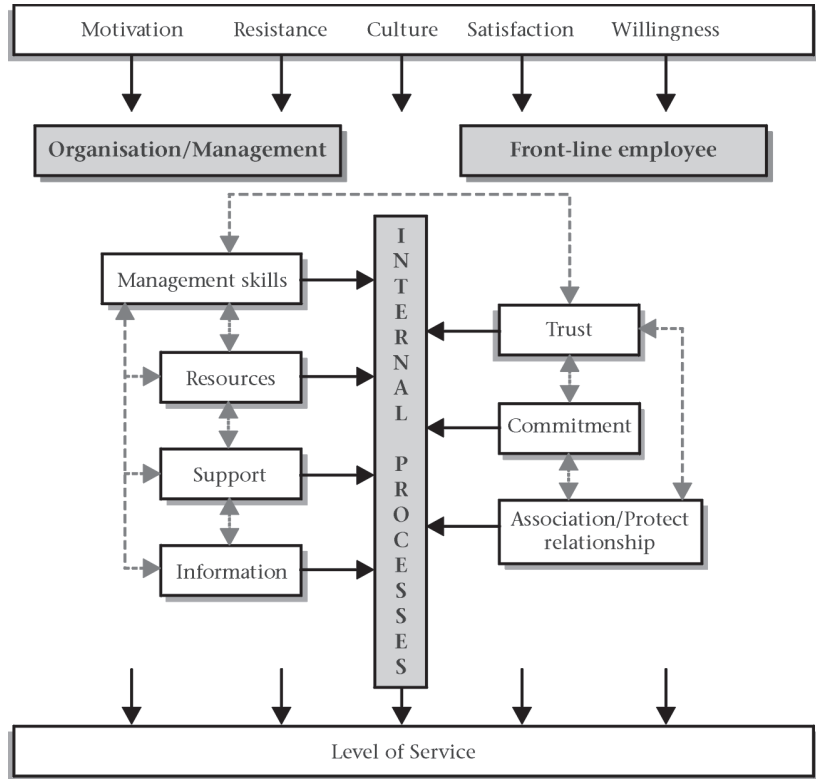

Figure 2: Process satisfaction model (PSM) 
As Pheng (1999) points out, the successful implementation of change strategies depends on the ability of middle and junior managers to convert such strategies into operational ones. Since inadequate managerial skills are some of the biggest barriers to effective change, it is essential to ensure that managers are capable and visible during a change process and are able to provide support when needed. Client service will only improve when managers show their interest and support to front-line personnel to render the quality service that is marked by availability, willingness and effectiveness.

The substantive model puts the responsibility for making internal organisational processes on the shoulders of both the employer/manager and the front-line employee unlike most models that highlight the manager or change makers' responsibility to facilitate change. This model is purposefully kept simple to be used in organisational communication to market the partnership in making internal processes more acceptable.

\section{Conclusions}

The study found the following:

- Front-line employees are de-motivated by the effects of unfair application of internal processes

- Employees are not committed to their jobs anymore although the SAPS try to keep employee commitment through rapid promotions as part of the process of addressing equity

- Policy implementation is the major cause of dissatisfaction with internal processes of promotion, transfers, and rewards

- Inadequate resources are prevailing in the ERPS. This situation contributes to culture that is leaning towards a pathological culture where employees feel that their careers are in the hands of forces beyond their control

- Front-line employees resist change aimed at improving service delivery because they do not agree with the processes applied to bring about change

- Willingness to render client service is dependent on employee satisfaction with the internal processes of the organisation

- A culture in which employees do not support each other, cheat each other through false reporting, and fear for safety due to inadequate resources are prevailing in the ERPS. This is further indication that the prevailing culture is leaning dangerously towards a pathological state.

The constructed model could be used as the much needed building block for change in the SAPS, other government departments, and organisations in the country. Managers can reduce change resistance with the aid of the basic concept of satisfaction with internal processes that is contained in the 'process satisfaction model'. In this way the study could make a contribution to the field of leadership studies.

The most important contribution the study makes is in the area of policy studies. The study, to some extent, may be regarded as a qualitative/interpretive policy analysis tool shedding light on the meanings frontline police officers attached to policy guiding management, training and human resource allocation by the SAPS.

\section{Limitations}

A notable limitation is that the study is at best an explorative one that managed to expose a 'weakness' in the surface of the police service. Since the research employed a case study design which involved only a small sample the knowledge gained from the research findings could not be generalized to other research settings.

\section{Recommendations}

One of the most important indicators (and sometimes the only indicator) used by citizens to evaluate the effectiveness of the SAPS, and for that matter that of other State Departments, is their perception of the quality of services rendered to them. Thus there is a direct relationship between the public's perception of the service provider and the quality of services received. Generally speaking poor service delivery will not only lead to dissatisfaction with services among the public and a growing feeling of distrust. It is thus of the utmost importance that state departments become results-focused. Realising this, various mechanisms was put into place to improve service delivery rendered by state departments. These included the Department of Public Service Administration's White paper on Transforming Public Service Delivery (Batho Pele) and also the Public Service Regulations (July 1999) require all government departments to establish and sustain service delivery programmes and emphasises that these programmes must be monitored regularly (http://www.iss.co.za/ PUBS/ CRIMEINDEX/01VOL5N03/critical.html)

Monitoring accountability in service delivery should thus be a major priority for state departments. This is especially true in view of the fact that achieving the Millennium Development Goals rely on improving the supply and quality of public services (Admin, Das \& Goldstein, 2008). Even more important is the fact that the South African Government is currently seriously challenged to meet the goals set by "Vision 2014", and the more recent "Apex Priorities" (http://www.info.gov.za/speeches /2008/08020811021001.htm). Because service delivery has become the kingpin in measuring the effectiveness of an entity it is essential to address the identified factors impacting negatively on services rendered by the SAPS. The most important recommendation is therefore to take the study further by developing the identified concepts of the Process Satisfaction Model into indicators that could be used to evaluate the situation and to monitor change.

\section{REFERENCES}

Bachiochi, P.D. \& Wiener, S.P. (2002). Qualitative data collection and analysis. In Basson, A. \& Nel, L. (1998). Customer service module for SAPS. Paarl: SAPS.

Basson, A. \& Nel, L. (1998). Customer service module for SAPS. Paarl: SAPS.

Barendse, L. (2002). ' $n$ Verkennende studie oor werknemers se persepsies van die organisasiekultuur van die SAPD George. Dissertation. Technikon South Africa (Unisa). Florida.

Bogdan, R. \& Biklen, S.K. (1998). Qualitative research for education. An introduction to theory and methods. Boston: Allyn \& Bacon.

Chetty, S. (2004). ICD hosts policing oversight accountability and transformation conference. SAPS Journal, March, 24 -29 .

Dantzker, M.L. (1997). Contemporary Policing: Personnel, issues and trends. Boston: Butterworth-Heinemann.

De Beer, E. (2002). The SAPS service charter is launched in Guguletu, Cape Town. SAPS Journal, 3(1), 12 - 13.

Denzin, N.K. \& Lincoln, Y. S. (2003) Strategies of qualitative inquiry. Second edition. London: Sage.

Department of Safety and Security. (1996). National crime prevention strategy. Available at: Internet:http://www.org. za/reports/1996/crime1.htm.

Department of Safety and Security. (1997). Community Policing: Policy framework and guidelines. Pretoria.

Department of Safety and Security. (1998). White Paper on Safety and Security: 1999 -2004. Pretoria: $1-12$.

Dick, B. (2002). Grounded theory: a thumbnail sketch. Available from: http://www.scu.edu.au/schools/gcm/ar/arp/grounded. html.

Egharevba, S. (2005). An investigation into African immigrants' experiences with the police in Finland. International Journal of Police Science and Management, 7(1), 44-61.

Eygelaar, S.J.D. (2004). The application of the excellence model to enhance military health service delivery and performance excellence. Dissertation. Johannesburg, University of Johannesburg

Flick, U. (2007) Managing quality in qualitative research. London: SAGE Publications. 
Fourie, M. \& Reynecke, F. (2001). Police Management: Beyond 2000. Pretoria.

Geldenhuys, K. (2005). Crime and crime prevention. Servamus, 98(2): 48-50.

Glaser, B. \& Strauss, A. (1967). The discovery of grounded theory. Chicago: Aldine.

Hartle, F (1995). How to Re-engineer Your Performance Appraisal Process. London: Kogan Page.

Heskett, J.L., Jones,.T.O., Loveman, G.W.,Sasser, W.E. \& Schlesinger, L.A. (1994). Putting the Service-Profit Chain to work, Harvard Business Review, March/April.

Holloway, I. \& Wheeler, S. (2002). Qualitative research in nursing. (2nd ed.). Oxford: Blackwell Science Ltd.

Ivkovic, S.K. (2003). To Serve and Collect: Measuring Police Corruption. Journal of criminal law and criminology, 93(2-3).

Johnson, G. \& Scholes, K. 1999. Exploring corporate strategy. 5th edition. London: Prentice Hall.

Kanstrup, A.M. (2002) Picture the Practice -Using Photography to Explore Use of Technology Within Teachers' Work Practices. Forum Qualitative Sozialforschung/Forum: Qualitative Social Research (on-line journal), 3(2). Available at www.qualitativeresearch.net/fqs-texte/2-02/2-02kanstrup-e.htm.

Kiley, J.D. (1997). The effects of organisational change in a public service organisation. Masters dissertation, University of South Africa, Pretoria.

Krause, B. (2004).The evaluation of the performance enhancement process (PEP) of the South African Police Service (SAPS): a case study at Parrow Police Station. Unpublished dissertation. University of Stellenbosh: Stellenbosh.

Liehr, P.R. \& Marcus, M.T. (2002). Qualitative approaches to research. In G. L. Wood \& J. Haber (Eds.). Nursing research. Methods, critical appraisal and utilization (5th ed). London: Mosby.

Locke, K. (2001). Grounded theory in management research. Thousand Oaks, California: SAGE Publications.

Marks, M. (2003). Transforming robocops? A case study of police organisational change. .Society in transition, 31(2): 144 - 161.

Martin, P. \& Nichols, J. (1987). Created a committed workforce. Institute for personnel management. In Mullins, L. (1999). Management and organisational behaviour. $5^{\text {th }}$ edition. Hong Kong: Prentice Hall.

McKenzie, I.K. (2005). Handbook of Policing. In T. Newburn (Ed.), International Journal of Police Science and Management, 7(1), 64-66.

McNeil, W.M. (1995). Evaluation of organisational change, development in the south African Police Service. Unpublished Master's dissertation, University of KwaZulu-Natal, Durban.1995.

Mouton, J. (2002). How to succeed in your Master's and Doctoral studies. Pretoria: Van Schaik.

Mourday, R.T., Porter, L.W., \& Steers, R.M. (1982). Employeeorganization linkages: The psychology of commitment, absenteeism and turnover. New York. Academic Press

Mullins, L. (1999). Management and organisational behaviour. $5^{\text {th }}$ edition. Hong Kong: Prentice Hall.

Murphy, E. \& Dingwall, R. (2003). Qualitative Methods and Health Policy Research. New York: Aldine De Gruyter.

Myers, M.D. (1997). Qualitative research in information systems. MIS Quarterly, 21(2), pp. 241-242.

Neuman, W.L. (1997). Social research methods: Qualitative and quantitative approaches. Third edition. Boston: Allyn \& Bacon.

O'Toole, K.M. (2004). Editorial: Police check. Third edition. Boston Globe. Mass. Dec 18, 2004, A.14.

Parry, K. W. (1998). Grounded Theory and Social Process: A new direction for Leadership Research. Leadership Quarterly, 9 (1), 85-105.169.

Pheng, L.S.(1999). Towards managerial efficiency: Back to 2,000year-old guiding principles. The Learning Organisation, 6(3), pp. 121-131.
Pretorius, E.M. (2006).The role of leadership in enhancing service delivery in local government (Unpublished Doctor in Philosophy) Faculty of Economic and Management Sciences, Johannesburg: University of Johannesburg.

Priest, H., Roberts, P. \& Woods, L. (2002). An overview of three different approaches to the interpretation of qualitative data. Part 1: Theoretical issues. Nurse Researcher, 10(1), pp. $30-43$

Punch, K.F. (1998). Introduction to social research. Quantitative \& qualitative approaches. Thousand Oaks, CA: Sage.

Puthpongsiriporn, S. \& Quang, T. (2004). Promoting a service culture for community policing in Thailand. International Journal of Police Science and Management, 7(1), $24-35$.

Schurink, W. J. (2004). Qualitative Research: Introducing key features of a humanistic approach to social science research: Lecture Ten: Data Analysis: Leadership in Performance and Change. Department of Human Resource Management, RAU, Johannesburg. 27 -28 February 2004.

Schurink, W. J. (2005). Considerations during qualitative research analysis: Brief notes. E-mail notes to D- and M- students. Pretoria. 14 July 2005.

Schwartz, G.J. (2004). The influence of training on attitudes towards clients in the East Rand Police Service. Unpublished Master's dissertation, Technikon South Africa, Florida.

Schwartz, G.J. (2007). Employees' social construction of client service. Unpublished dissertation. University of Johannesburg: Johannesburg.

Silverman, D. (2000). Doing qualitative research. A practical handbook. London: Sage Publications.

Smit, J.M. (1996). A critical assessment of the South African Police Service culture from a learning perspective. Dissertation. Johannesburg, Rand Afrikans University.

Smith, H. (2004). South African knowledge managers' social construction of knowledge management and human resources: a grounded theory approach. (Unpublished dissertation). Johannesburg: Rand Afrikaans University

South African Police Service.(2002). Resolution 7/2002: circular 25/7/5/14/1 dated 2002-09-04. Unpublished document. Pretoria: SAPS.

Strauss, A. \& Corbin, J. (1990). Basics of qualitative research. Grounded theory procedures and techniques. London: SAGE Publications. 206.

Stevens, P. \& Yach, D.M. (1995). Community Policing in action: a practitioners guide. Cape Town: Juta.

Swanepoel, B., Erasmus, B., van Wyk, M. \& Schenk, H. (2000). South African human resource management. Theory and practice. Cape Town: Juta.

Swanson, R. A. \& Holton, E.F. (1997). Human Resource Development research handbook: Linking research and practice. San Francisco: Berrett-Koehler Publishers.

Taylor, S.J. \& Bogdan, R. (1998). Introduction to qualitative research methods: A guidebook and resource. Third edition. New York: John Wiley \& Sons.

Torrington, D and Hall, L (1998) Human Resources Management. London: Prentice Hall.

Van Graan, J. (2005). Obstacles impeding the transformation process in the South African Police Service. Unpublished dissertation. University of South Africa. Pretoria.

Veldsman, T.H. (2002). Into the people effectiveness arena: Navigating between chaos and order. Randburg: Knowledge Resources (Pty) Ltd.

Watson, T.J. (2003). Sociology, work and industry. Fourth edition. London: Routledge.

Wood, D.B. (2005). In L.A., trying to keep a lid on racial strife. Christian Science Monitor. Boston, Mass. Mar 10, 2005, 03. 